\title{
Using Bayesian Networks for Quantifying Domino Effect Probability in a Hydrocarbon Processing Area
}

\author{
Duenas Santana $\mathrm{JA}^{1 *}$, Arana $\mathrm{YC}^{2}$, Boza Matos $\mathrm{YC}^{3}$, Furka ${ }^{4}$, Furka $\mathrm{S}^{4}$, \\ Orozco JL ${ }^{1}$, Febles JS ${ }^{1}$, Lantigua $\mathrm{DF}^{3}$ and Gonzalez Gomez $\mathbf{0}^{2}$ \\ ${ }^{1}$ Chemical Engineering Department, University of Matanzas, Cuba \\ ${ }^{2}$ Chemical Engineering Degree student, University of Matanzas, Matanzas, Cuba \\ ${ }^{3}$ Master's degree student, University of Matanzas, Matanzas, Cuba \\ ${ }^{4}$ Department of Physical and Theoretical Chemistry, Comenius University in Bratislava, Slovak \\ Republic
}

\section{Research Article}

Volume 5 Issue 3

Received Date: September 01, 2021

Published Date: September 27, 2021

DOI: $10.23880 /$ ppej-16000274

*Corresponding author: Julio Ariel Dueñas Santana, Chemical Engineering Department, Faculty of Technical Sciences, University of Matanzas. Carretera a Varadero km 3,5. Matanzas, CP 44 740, Cuba, Tel: +5352389846; Email: julio.duenas94@gmail.com

\section{Abstract}

Accidents in process industries include fires, explosions, or toxic releases depending on the spilled material properties and ignition sources. One of the worst phenomena that may occur is the called domino effect. This triggers serious consequences on the people, the environment, and the economy. That is why the European Commission defined the domino effect prediction as a mandatory challenge for the years ahead. The quantification of the domino effect probability is a complex task due to the multiple and synergic effects among all accidents that should be included in the analysis. However, these techniques could be integrated with others in order to represent the domino effect occurrence reliably. In this matter, artificial intelligence plays a vital role. Bayesian networks, as one of the artificial intelligence nets, have been widely applied for domino effect likelihood determination. This research aims to provide a guide for quantifying domino effect probability using Bayesian networks in a hydrocarbon processing area. For this purpose, a four-step model is proposed integrating some classical risk analysis techniques with Bayesian networks. Moreover, this methodology is applied to an actual hydrocarbon storage and processing facility. After that, the joint probability can reach $9.37 \%$ for the process unit tank 703 which storages naphtha. Hence, safety management plans must be improved in this area for reducing this actual risk level. Finally, this research demonstrates how Artificial intelligence techniques should be integrated with classical ones in order to get more reliable results.

Keywords: Industrial Accidents; Bayesian Networks; Domino Effect; Safety Management; Fire; Explosion

\section{Introduction}

Accidents in process industries include fires, explosions or toxic releases depending on the spilled material properties and ignition sources. One of the worst phenomena that may occur is the called domino effect $[1,2]$. Cascading effects of accidents have been widely studied in specialized literature. Authors coincide in the concept of the domino effect as a sequence of accidents where the primary scenario leads to new scenarios and the consequences of the whole chain of events is higher than the single primary event [3,4-7]. That is why European Commission established the domino effect 
prediction as a mandatory challenge for the years ahead [8].

The quantification of the domino effect probability is a complex task due to the multiple and synergic effects among all accidents that should be included in the analysis. Then, classical risk analysis techniques do not provide the most credible or reliable results regarding domino effect likelihood, such as Past Event Analysis, Event Tree or Fault Tree [5,9]. However, these techniques could be integrated with others in order to represent the domino effect occurrence reliably. In this matter, artificial intelligence plays a vital role. Bayesian networks, as one of the artificial intelligence nets, have been widely applied for domino effect likelihood determination. Dueñas Santana, et al. [5] studied a new integrated BayesianPetri approach for quantifying individual impact due to fire and explosion accidents. Moreover, Dueñas Santana, et al. [6] proposed a new Fuzzy-Bayesian approach for determining failure probability due to pool fire. Additionally, Bayesian networks have been declared in other researches as the most suitable tools for domino effect representation [10-15]. Hence, this research aims to provide a guide for quantifying domino effect probability using Bayesian networks in a hydrocarbon processing area.

\section{Methodology}

This section focuses on explaining the developed methodology (Figure 1) for the present research. This is a four-step model which integrates the Scenario Simulation using the ALOHA software, the Probit Equations and the development of Bayesian Networks.

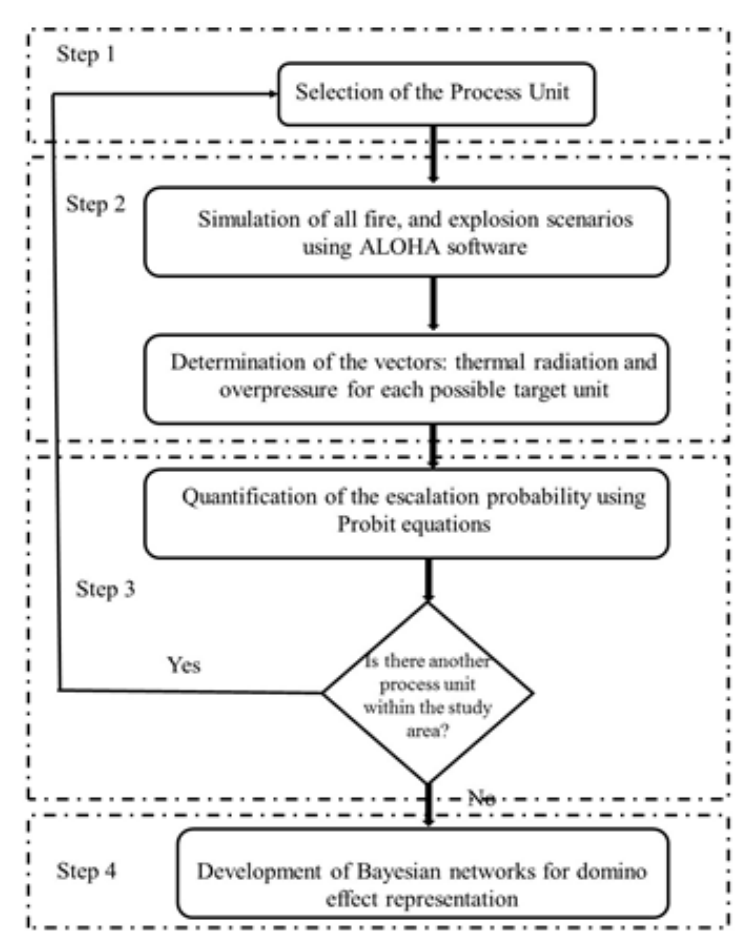

Figure 1: Proposed methodology in the framework of this research.

The first step aims to select the process units according to its potential for detonating fire and explosion accidents [7]. Next, the second stage is related to the scenario simulation using the ALOHA software, for determining the escalation vectors (thermal radiation and overpressure), which leads to the definition of credible domino sequences comparing these values to threshold ones. Subsequently, step 3 is related to the determination of escalation probability using the Probit Equations proposed by Reniers and Cozzani [16]. Finally, step 4 focuses on the development of the Bayesian networks for the domino effect likelihood quantification.

\section{Step 1: Selection of the Process Unit}

This step consists of the division of the study area into process units, based on their potential of generating damages themselves. In other words, each process unit must contain a hazardous material that may be involved in the case of an accident. Furthermore, a technological criterion may be considered to give priority to parts of the process which have been involved in previous incidents or have a higher risk of producing fire or explosions $[5,17]$. 


\section{Petroleum \& Petrochemical Engineering Journal}

\section{Step 2: Simulation of the Scenarios and Determination of the Escalation Vectors}

Fire and explosion accidents would depend on the chemical and physical properties of the storage material in every process unit $[18,19]$. ALOHA $^{\odot}$ software is a prestigious tool that determines the scope of thermal radiation (due to fires) and overpressure (due to explosions). ALOHAC was developed jointly by two international companies: The National Oceanic and Atmospheric Administration (NOAA) and the Environmental Protection Agency (EPA). In addition to this, ALOHA(C has been recognized by the Ministry of Science, Technology and Environment in Cuba (CITMA) as the recommended software for this kind of study $[4,20]$. More information about the described software can be found in the ALOHAC User's Handbook (2016). Additionally, ALOHA established the following Levels of Concern (LOC):

For thermal radiation, three LOC values are established:

$>$ Red Threat Zone: $10 \mathrm{~kW} / \mathrm{m}^{2}$ : potentially lethal within 60 seconds.

$>$ Orange Threat Zone: $5 \mathrm{~kW} / \mathrm{m}^{2}$ : second degree burns within 60 seconds

> Yellow Threat Zone: $2 \mathrm{~kW} / \mathrm{m}^{2}$ : pain within 60 seconds.
In the case of overpressure due to the explosion of a vapor cloud:

$>$ Red Threat Zone: 8.0 psi: destruction of buildings.

$>$ Orange Threat Zone: 3.5 psi: serious injury likely.

$>$ Yellow Threat Zone: 1.0 psi: shatters glass.

\section{Step 3: Quantification of the Escalation Probability}

The quantification of the escalation probability for fire and explosion accidents is key in domino effect analysis. Thus, probit Equations which calculate necessary parameters are described in the literature [16]. The escalation probability represents the potential of a first leading accident (primary accident) that results in a chain of events [5]. The Probit Equations for determining the escalation probability for atmospheric storage vessels are shown in Table 1 . When the probit value is obtained, it is transformed into a probability value according to Equation 1.

$$
P=\frac{1}{\sqrt{2 p}} \int_{-\infty}^{Y-5} \exp \left[-\frac{V^{2}}{2}\right] d V
$$

\begin{tabular}{|c|c|c|c|}
\hline Escalation vector & Threshold value & Probability model & Equation \\
\hline \multirow{3}{*}{ Thermal radiation } & \multirow{3}{*}{$\mathrm{I}>15 \mathrm{~kW} / \mathrm{m}^{2}$} & $Y=9.25-1.847 \cdot \ln (\mathrm{ttf} / 60)$ & 2 \\
\cline { 2 - 4 } & & $\begin{array}{l}\ln (\mathrm{ttf})=-1.13 \cdot \\
\ln (I)-2.67 \cdot 10^{-5} V+9.9\end{array}$ \\
\hline Overpressure & $\mathrm{P}>22 \mathrm{kPa}$ & $Y=-18.96+2.44 \cdot \ln \left(P_{S}\right)$ & 4 \\
\hline
\end{tabular}

Table 1: Vulnerability models for atmospheric storage tanks.

Y: probit value for escalation given the primary scenario; $t \mathrm{tf}$ : time to failure, seconds; I: radiation intensity on the target equipment $\mathrm{kW} / \mathrm{m}^{2}$; V: equipment volume $\mathrm{m}^{3}$; Ps: peak static overpressure on the target equipment $\mathrm{Pa}$.

In the manner described, the proposed methodology determines the probability of escalation for further use.

\section{Step 4: Development of Bayesian Network for Domino Effect Representation}

A Bayesian Network is an acyclic graphic used for reasoning under uncertainty, in which nodes represent variables and are connected by addressing arcs [12,21-23]. The development of a Bayesian Network has a main aim: the quantification of domino effect probabilities corresponding to each escalation level. This is possible due to the inclusion of specific nodes proposed by Khakzad, et al. [10].

Arcs denote dependencies of causal relations between nodes, while conditional probability tables determine the type and force of every dependency [22,23]. One of the main advantages of Bayesian networks is their mathematical base in Bayes' rule according to Equation 5.

$$
P(A / B)=P(A) \cdot \frac{P(B / A)}{P(B)}(5)
$$

This means that the conditional probability of A given B, $P(A / B)$, also named posterior probability due to its derivation from the specified value of $\mathrm{B}$ probability; is equivalent to the product of the probability of $\mathrm{A}, P(A)$, with the Bayes' factor or probabilities relation, which is defined as the probability of $\mathrm{B}$ given the event $\mathrm{A}, P(B / A)$, divided by the probability of $\mathrm{B}, P(B)$. 


\section{Petroleum \& Petrochemical Engineering Journal}

\section{Results and Discussion}

In this section the application of the proposed methodology is applied in a hydrocarbon storage area of Matanzas, Cuba. Moreover, the results will be thoroughly explained and compared with existing literature.

\section{Results of the Selection of Process Units (Step 1)}

The first step aims to the selection of the appropriate process units. Table 2 shows the technological characteristics of the studied tanks, where all the process units are atmospheric vessels.

\begin{tabular}{|c|c|c|c|c|c|}
\hline Process Unit & $\begin{array}{c}\text { Storage } \\
\text { material }\end{array}$ & $\begin{array}{c}\text { Nominal volume } \\
\mathbf{( m}^{\mathbf{3}} \mathbf{n}\end{array}$ & Diameter (m) & $\begin{array}{c}\text { Operational height } \\
(\mathbf{m})\end{array}$ & $\begin{array}{c}\text { Shape thickness } \\
(\mathbf{m m})\end{array}$ \\
\hline TK 101 & Crude oil & 5000 & 22.81 & 10.31 & 6 \\
\hline TK 102 & Crude oil & 5000 & 22.85 & 10.29 & 6 \\
\hline TK 103 & Crude oil & 5000 & 20.92 & 12.28 & 6 \\
\hline TK 104 & Crude oil & 5000 & 20.89 & 12.28 & 6 \\
\hline TK 701 & Naphtha & 200 & 6.62 & 5.6 & 6 \\
\hline TK 702 & Naphtha & 200 & 6.62 & 5.58 & 6 \\
\hline TK 703 & Naphtha & 200 & 6.95 & 5 & 6 \\
\hline TK 704 & Naphtha & 200 & 6.97 & 5 & \\
\hline
\end{tabular}

Table 2: Technological characteristics of process units.

Every process unit has itself the capability of generating fire and explosion accidents, so, the next step is related to the identification of possible scenarios and simulation of these for quantifying escalation vectors.

\section{Results of the Simulation of the Scenarios and Determination of the Escalation Vectors (Step 2)}

This step is related to the simulation of fire and explosion scenarios to quantify the escalation vectors: thermal radiation and overpressure. These results are shown in Tables $3 \& 4$.

\begin{tabular}{|c|c|c|c|c|c|c|c|c|}
\hline \multirow{2}{*}{ Process Units } & \multicolumn{9}{|c|}{ Thermal Radiation $\left(\mathbf{k W} / \mathbf{m}^{\mathbf{2}}\right.$ ) } \\
\cline { 2 - 10 } & $\mathbf{1 0 1}$ & $\mathbf{1 0 2}$ & $\mathbf{1 0 3}$ & $\mathbf{1 0 4}$ & $\mathbf{7 0 1}$ & $\mathbf{7 0 2}$ & $\mathbf{7 0 3}$ & $\mathbf{7 0 4}$ \\
\hline 101 & & 34 & 35 & 21 & 41 & 32 & 25 & 18 \\
\hline 102 & 35 & & 25 & 38 & 13 & 12 & 11 & 9 \\
\hline 103 & 34 & 25 & & 37 & 30 & 39 & 41 & 41 \\
\hline 104 & 21 & 38 & 37 & & 12 & 13 & 13 & 13 \\
\hline 701 & 8 & 2 & 5.2 & 1.7 & & 38 & 14 & 7 \\
\hline 702 & 7 & 2 & 8 & 2 & 43 & & 40 & 17 \\
\hline 703 & 4.8 & 1.7 & 9 & 2.2 & 16 & 40 & & 45 \\
\hline 704 & 3 & 1.45 & 8.2 & 2 & 7.5 & 15 & 41 & \\
\hline
\end{tabular}

Table 3: Thermal radiation among process units.

\begin{tabular}{|c|c|c|c|c|c|c|c|c|}
\hline \multirow{2}{*}{ Process Units } & \multicolumn{9}{|c|}{ Overpressure (psi) } & $\mathbf{7 0 2}$ \\
\cline { 2 - 10 } & $\mathbf{1 0 1}$ & $\mathbf{1 0 2}$ & $\mathbf{1 0 3}$ & $\mathbf{1 0 4}$ & $\mathbf{7 0 1}$ & $\mathbf{7 0 2}$ & $\mathbf{7 0 3}$ & $\mathbf{7 0 4}$ \\
\hline 701 & 6.36 & 6.36 & 6.36 & 6.36 & & 6.36 & 6.36 & 6.36 \\
\hline 702 & 6.36 & 6.36 & 6.36 & 6.36 & 6.36 & & 6.36 & 6.36 \\
\hline 703 & 6.36 & 6.36 & 6.36 & 6.36 & 6.36 & 6.36 & & 6.36 \\
\hline 704 & 6.36 & 6.36 & 6.36 & 6.36 & 6.36 & 6.36 & 6.36 & \\
\hline
\end{tabular}

Table 4: Overpressure among process units. 


\section{Petroleum \& Petrochemical Engineering Journal}

In subarea 1 (containing the crude oil tanks), the highest values of thermal radiation are emitted from tank 101 regarding tanks 103 and 701 with $35 \mathrm{~kW} / \mathrm{m}^{2}, 41 \mathrm{~kW} / \mathrm{m}^{2}$ respectively. Next, tank 103 generates thermal radiation of $41 \mathrm{~kW} / \mathrm{m}^{2}$ with respect to tanks 703 and 704 . In subarea 2 (containing the naphtha tanks), the highest value of thermal radiation is $45 \mathrm{~kW} / \mathrm{m}^{2}$ and it is generated from tank 703 to tank 704; after that, the value of $43 \mathrm{~kW} / \mathrm{m}^{2}$ from tank 702 with respect to tank 701 . Similar values were obtained by Dueñas Santana et al., (2021b). These values are enough for triggering the escalation in this area (three times higher than the threshold values) and this is due to the high flammability and volatility of these substances.
In the case of a Vapor Cloud Explosion (VCE) occurs, the overpressure generated is around $6.36 \mathrm{psi}(43.85 \mathrm{kPa})$ which means a very high possibility of escalation. These results are similar for those obtained for Dueñas Santana et al. [6].

\section{Results of the Quantification of the Escalation Probability (Step 3)}

Escalation probability gives a criterion needed for linking the nodes into the Bayesian networks. That is why the determination of these values is key in the framework of this research. These values are shown in Tables $5 \& 6$.

\begin{tabular}{|c|c|c|c|c|c|c|c|c|}
\hline \multirow{2}{*}{ Process Units } & \multicolumn{9}{|c|}{ Escalation Probability due to Thermal Radiation } \\
\cline { 2 - 9 } & $\mathbf{1 0 1}$ & $\mathbf{1 0 2}$ & $\mathbf{1 0 3}$ & $\mathbf{1 0 4}$ & $\mathbf{7 0 1}$ & $\mathbf{7 0 2}$ & $\mathbf{7 0 3}$ & $\mathbf{7 0 4}$ \\
\hline 101 & & 0.88 & 0.89 & 0.56 & 0.9 & 0.79 & 0.61 & 0.34 \\
\hline 102 & 0.89 & & 0.7 & 0.92 & 0.14 & 0.1 & 0.07 & 0.03 \\
\hline 103 & 0.88 & 0.7 & & 0.91 & 0.75 & 0.88 & 0.9 & 0.9 \\
\hline 104 & 0.56 & 0.92 & 0.91 & & 0.1 & 0.14 & 0.14 & 0.14 \\
\hline 701 & 0.03 & $1.08 \mathrm{E}-06$ & 0.003 & 0 & & 0.87 & 0.18 & 0.01 \\
\hline 702 & 0.01 & $1.08 \mathrm{E}-06$ & 0.03 & $1.08 \mathrm{E}-06$ & 0.92 & & 0.89 & 0.3 \\
\hline 703 & 0.001 & 0 & 0.05 & $2.83 \mathrm{E}-06$ & 0.26 & 0.89 & & 0.93 \\
\hline 704 & $4.98 \mathrm{E}-01$ & 0 & 0.03 & $1.08 \mathrm{E}-02$ & 0.01 & 0.22 & 0.9 & \\
\hline
\end{tabular}

Table 5: Escalation probability due to thermal radiation among process units.

\begin{tabular}{|c|c|c|c|c|c|c|c|c|}
\hline \multirow{2}{*}{ Process Units } & \multicolumn{9}{|c|}{ Escalation Probability Due To Overpressure } \\
\cline { 2 - 10 } & 101 & 102 & 103 & 104 & 701 & 702 & 703 & 704 \\
\hline 701 & 0.98 & 0.98 & 0.98 & 0.98 & & 0.98 & 0.98 & 0.98 \\
\hline 702 & 0.98 & 0.98 & 0.98 & 0.98 & 0.98 & & 0.98 & 0.98 \\
\hline 703 & 0.98 & 0.98 & 0.98 & 0.98 & 0.98 & 0.98 & & 0.98 \\
\hline 704 & 0.98 & 0.98 & 0.98 & 0.98 & 0.98 & 0.98 & 0.98 & \\
\hline
\end{tabular}

Table 6: Escalation probability due to overpressure among process units.

The highest values of escalation probability correspond to the highest values of escalation vectors: thermal radiation and overpressure. The VCE occurrence leads to a more likely escalation due to the consistent high value of 0.98 for escalation probability in this case, respect to all process units. Similar values were obtained for Dueñas Santana et al. [5,6].

\section{Results of the Development of Bayesian Networks For Domino Effect Representation (Step 4)}

Bayesian networks (BN) aim to quantify the domino effect probability. For determining the most reliable net architecture based on the results of previous steps, five Bayesian networks are developed:

1. BN \#1: This BN is developed considering a pool fire as the primary event in the tank 703 (naphtha storage) and secondary or tertiary process unit escalation pattern through thermal radiation vector triggering to several pool fires.

2. BN \#2: This BN is developed considering a VCE as a primary event in tank 703 (naphtha storage) and the escalation pattern depending on the overpressure vector triggering to several VCEs.

3. BN \#3: This BN is developed considering a VCE as a primary event in tank 703 (naphtha storage) and the 
escalation pattern depending on the overpressure vector for naphtha-storage tanks and thermal radiation for crude-storage tanks triggering several pool fires and VCEs.

4. BN \#4: This BN is developed considering a pool fire as a primary event in tank 103 (crude oil storage) and the escalation pattern depending on the thermal radiation vector triggering several pool fires.

5. BN \#5: This BN is developed considering a pool fire as a primary event in tank 103 (crude oil storage) and the escalation pattern depending on the overpressure vector for naphtha-storage tanks and thermal radiation for crude-storage tanks triggering several pool fires and VCEs.

Figure 2 shows the developed BN \#1. In this BN, tank 703 is the primary process unit; tanks 103, 702 and 704 are the secondary units; tanks 102, 104, and 701 are the tertiary units; and finally, the tank 101 and heat exchangers in the area are considered quaternary units. The possible secondary units due to thermal radiation escalation from tank 703 are just three because of the position of this vessel with respect to the others.

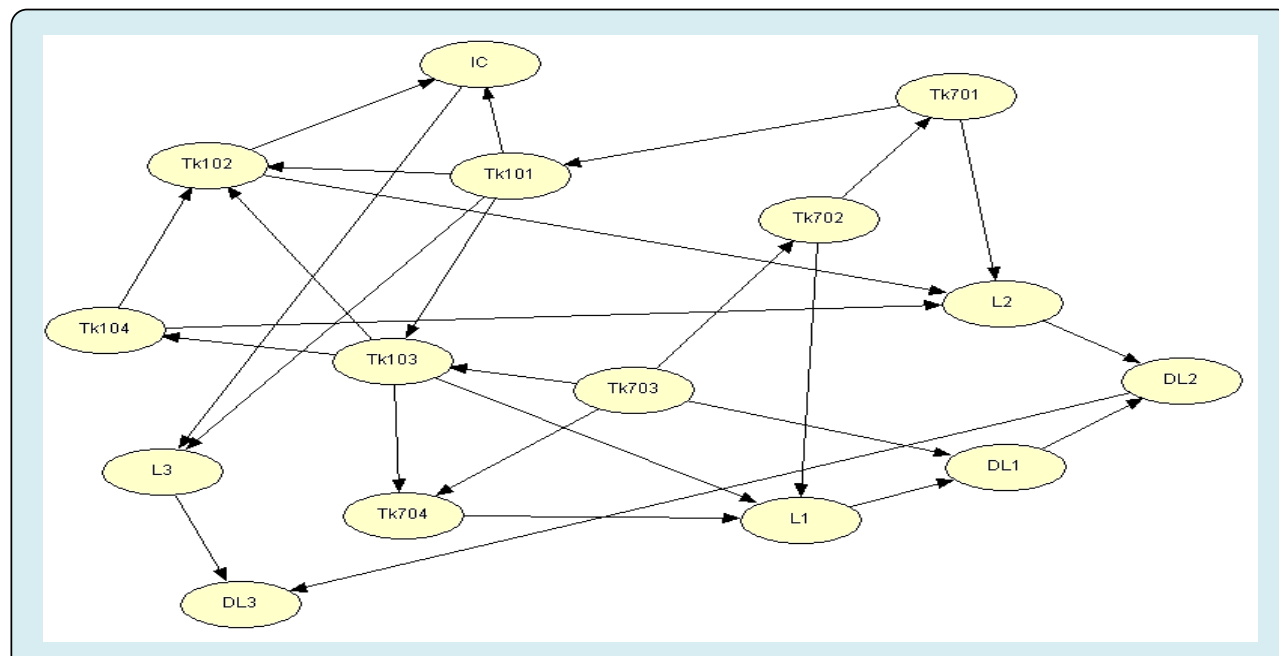

Figure 2: BN \#1 developed from a starting pool fire in tank 703.

Figures $3 \& 4$ show the results related to the probability of accident in each process unit corresponding to BN \#1.

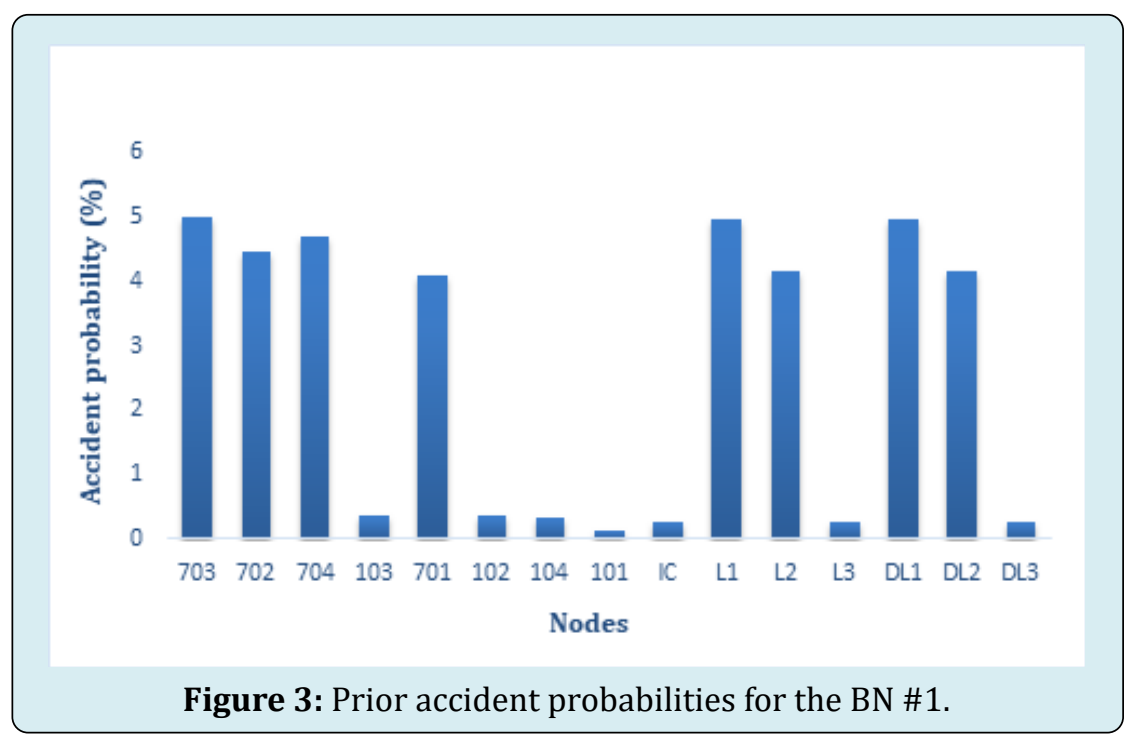




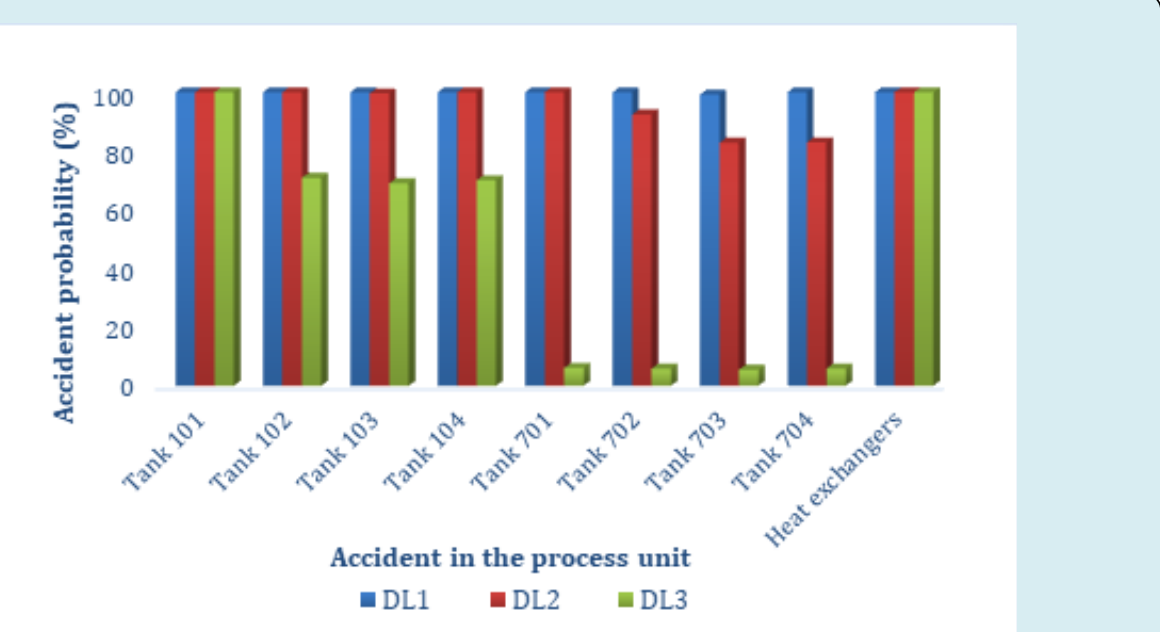

Figure 4: Accident probabilities for the BN \#1 if an accident occurs in a process unit.

For the developed BN \#1, the accident probabilities are around $5 \%$, these values are high according to specialized literature $[5,6,13,24,25]$. Though tank 703 has low capacity, the storage material is naphtha which is a highly flammable and volatile substance. Thus, there is a high probability of developing this domino effect pattern in the area. The domino effect first level probability (DL1) is $5 \%$, for a second level (DL2), 4.15\% and for the third level (DL3), $0.27 \%$. In the case of an accident occur in any of the process units, the BN allows updating the probabilities knowing this new event. Then, the domino effect first level likelihood is $100 \%$ which means that the possibility of occurrence of this phenomenon is the highest possible. Thus, this domino effect sequence is very likely. For BN \#2 and BN \#3, similar results were obtained. However, the sequence represented in the BN\#1 is the most probable in the domino effect occurrence.

Figure 5 shows the developed BN \#4. In this BN, tank 103 is the primary process unit; tanks 101, 104, 703 and 704 are the secondary units; tanks $102,702,701$ and heat exchangers are the tertiary units.

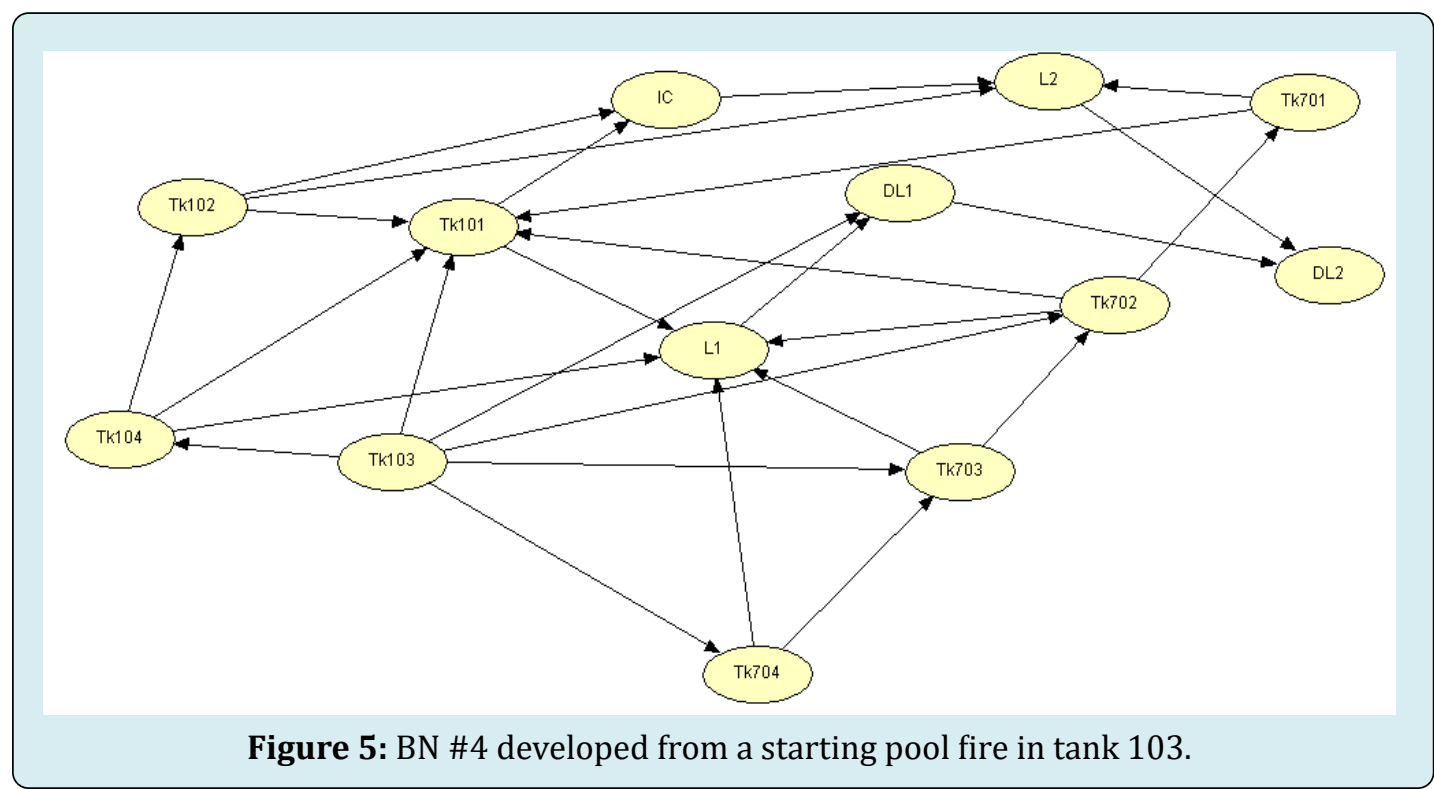

Figures 6 \& 7 show the results related to the probability of an accident in each process unit corresponding to BN \#4 

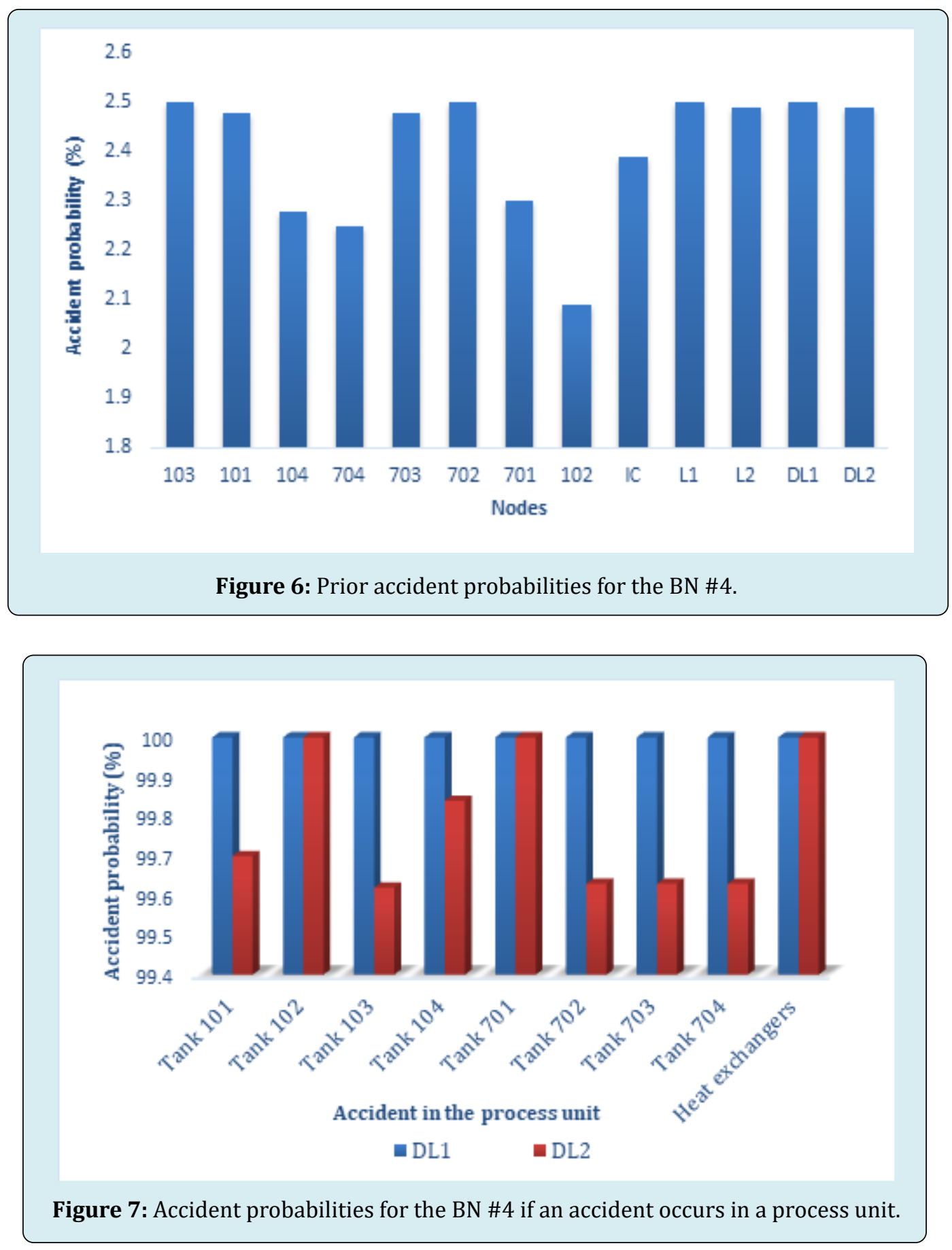

The accident probability for the secondary process units is less than $2.5 \%$ but is still high according to specialized literature. The development of this specific sequence is less probable than that in the naphtha-storage tanks due to the naphtha can lead also to VCEs, not just pool fires (higher flammability and volatility). For all cases is almost completely likely that another accident can occur if a previous one happened in tank 103. The domino effect probability is higher than $99 \%$ for all escalation levels. For the BN \#5, similar results were obtained.

Figure 8 shows a comparison among all domino effect level probabilities considering a starting event in tank 703 and in tank 103 respectively for all developed BNs. 


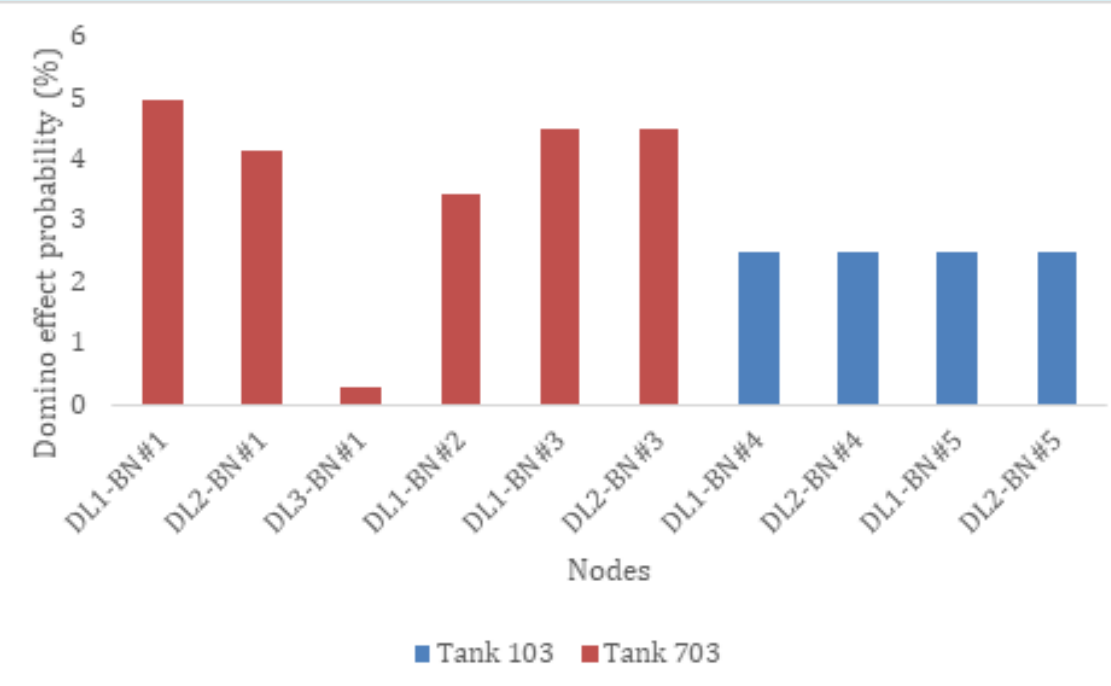

Figure 8: Comparison among all domino effect level probabilities considering a starting event in tank 103 and in tank 703

Moreover, the joint probability is $9.37 \%$ for tank 703 and $5.00 \%$ for tank 103 . Thus, tank 703 is more dangerous than tank 103 considering domino effect propagation because has more probabilities for the occurrence of this phenomenon. This is due to the high flammability and volatility of the naphtha regarding to crude oil. These results are similar to those obtained for Dueñas Santana, et al. [5].

\section{Conclusions}

Bayesian networks are a vital tool for quantifying domino effect probability in a hydrocarbon storage area. BNs allow to consider the possible interactions among all credible accidents and to determine the most likely domino sequence in an area. In the analyzed case study, the most dangerous process unit for domino effect detonation is tank 703 which storages naphtha. The joint probability can reach $9.37 \%$ for this process unit. BNs predict the domino effect level probabilities if an accident occurs in any process units, these values are considered the highest possible, because they can reach $100 \%$ in some cases, and in others higher than $99 \%$. Thus, safety management plans must be improved in this area for reducing this actual risk level. This research demonstrates how Artificial intelligence techniques should be integrated with classical ones in order to get more reliable results.

\section{References}

1. Jie L, Genserik R, Cozzani V, Faisal K (2017) A bibliometric analysis of peer-reviewed publications on domino effects in the process industry. International Journal of Environmental Research and Public Health 29.
2. Kardell L, Loof M (2014) QRA with respect to domino effects and property damage. Division of Risk Management and Societal Safety, Lund University, Sweden, pp: 92.

3. Cozzani V, Reniers G (2021) Dynamic risk assessment and management of domino effects and cascading events in the process industry. $1^{\text {st }}($ Edn.), Elsevier, pp: 406.

4. Dueñas Santana JA, González Miranda A, Orozco JL, Cuba Arana Y, Febles Lantigua D, et al. (2020) How to Determine Individual Risk Due to Toxic, Fire, and Explosion Accidents in a Hydrocarbon Processing Area? International Journal of Petroleum Technology 7: 60-73.

5. Dueñas Santana JA, Cuba Arana Y, Barrera González MC, Orozco JL (2021) How to determine the dangerous potential of accidents to domino effect detonation in a hydrocarbon processing area? Global Journal of Chemical Sciences 1(2).

6. Dueñas Santana JA, Orozco JL, Febles Lantigua D, Furka D, Furka S, et al. (2021) Using Integrated Bayesian-Petri Net methodology for individual impact assessment of domino effect accidents. Journal of Cleaner Production 294: 126236.

7. Dueñas Santana JA., Orozco JL, Furka D, Furka S, Boza Matos YC, et al. (2021) A new Fuzzy- Bayesian approach for the determination of failure probability due to thermal radiation in domino effect accidents. Engineering Failure Analysis 120: 105106.

8. Poljanšek K, Marin FM, De Groeve T, Clark I (2017) Science for disaster risk management 2017: knowing 


\section{Petroleum \& Petrochemical Engineering Journal}

better and losing less. JRC Publications Repository.

9. Alileche N, Olivier D, Estel L, Cozzani V (2016) Analysis of domino effect in the process industry using the event tree method. Safety Science 97: 10-19.

10. Khakzad N, Khan F, Amyotte P, Cozzani V (2013) Domino Effect Analysis Using Bayesian Networks. Risk Analysis 33(2): 292-306.

11. Leoni L, Toroody AB, De Carlo F, Paltrinieri N (2019) Developing a risk-based maintenance model for a Natural Gas Regulating and Matering Station using Bayesian Network. Journal of Loss Prevention in the Process Industries 57: 17-24.

12. Shi J, Zhu Y, Khan F, Chen G (2018) Application of Bayesian Regularization Artificial Neural Network in explosion risk analysis of fixed offshore platform. Journal of Loss Prevention in the Process Industries 57: 131-141.

13. Simon C, Mechri W, Capizzi G (2019) Assessment of Safety Integrity Level by simulation of Dynamic Bayesian Networks considering test duration. Journal of Loss Prevention in the Process Industries 57: 101-113.

14. Zarei E, Khakzad N, Cozzani V, Reniers G (2019) Safety analysis of process systems using Fuzzy Bayesian Network (FBN). Journal of Loss Prevention in the Process Industries 57: 7-16.

15. Kabir S, Papadopulos Y (2019) Applications of Bayesian network and Petri nets in safety, reliability and risk assessments: A review. Safety Science 115: 154-175.

16. Reniers G, Cozzani V (2013) Domino Effects in the Process Industries. Modeling, Prevention and Managing. $1^{\text {st }}($ Edn.), Elsevier, pp: 384.

17. Casal J (2008) Evaluation of the Effects and Consequences of Major Accidents in Industrial Plants. Industrial Safety Series. $2^{\text {nd }}($ Edn.), Elsevier, pp: 570.

18. Gyenes Z, Wood M, Struckl M (2017) Handbook of Scenarios for Assessing Major Chemical Accident Risks. JRC Technical Reports 116.

19. Jaderi F, Ibrahim Z, Reza M (2019) Criticality analysis of petrochemical assets using risk based maintenance and the fuzzy inference system. Process Safety Environmental Protect 121: 312-325.

20. Orozco JL, Caneghem J, Hens L, González L, Lugo R, et al. (2019) Assessment of an ammonia incident in the industrial area of Matanzas. Journal of Cleaner Production 222: 934-941.

21. Villa V, Cozzani V (2016) Application of Bayesian Networks to Quantitative Assessment of Safety Barriers' Performance in the Prevention of Major Accidents. Chemical Engineering Transactions 53: 151-156.

22. Conrady S, Jouffe L (2015) Bayesian Networks \& Bayesialab-A Practical Introduction for Researchers. $1^{\text {st }}($ Edn.), Bayesia Singapore Pte. Ltd..

23. Scutari M, Denis JB (2015) Bayesian Networks with Examples in R. $1^{\text {st }}($ Edn.), CRC Press, Taylor and Francis Group, pp: 241.

24. Cai B, Liu Y, Fan Q (2018) A multiphase dynamic Bayesian networks methodology for the determination of safety integrity levels. Reliability Engineering and System Safety 150: 105-115.

25. Yazdi M (2019) A review paper to examine the validity of Bayesian network to build rational consensus in subjective probabilistic failure analysis. International Journal of System Assurance Engineering and Management 10: 1-18. 